\title{
Rancang Bangun Sistem Keamanan Parkir Berbasis Random Password dan Image Processing Menggunakan Optical Character Recognition (OCR)
}

\author{
Fajar Dwima W' ${ }^{1}$, Diana Rahmawati, S. T. , M. T ${ }^{2}$, Kunto Aji W. , S. T. , M. T ${ }^{3}$ \\ Jurusan Teknik Elektro, Fakultas Teknik, Universitas Trunojoyo Madura \\ Jl. Raya Telang Kamal, Bangkalan Madura 60111 Indonesia \\ E-mail: fajardwima@gmail.com,dianarahmawti@gmail.com, kunto.utm@gmail.com
}

\begin{abstract}
Abstrak
Sistem pengelolaan tempat parkir pada saat ini masih kurang maksimal dalam pemanfaatan lahan parkir, keamanan dan efisiensi waktu. Pada penelitian ini, akan dirancang sistem parkir berbasis image processing, dan menggunakan dua parameter masukan yaitu menggunakan kamera untuk mendeteksi plat nomor kendaraan yang diubah dalam bentuk teks dan sandi (Enkripsi dalam bentuk barcode) yang didapat secara acak. Dua parameter yang di masukan ke dalam basis data mysql oleh sistem di pintu masuk, yaitu plat nomor dan sandi, inputan ini digunakan untuk kendaraan yang akan keluar, sistem mencocokan antara plat nomor kendaraan dan sandi, jika plat nomor dan sandi sesuai dengan basis data maka memenuhi kondisi dan pintu keluar (Motor Servo) terbuka. Sistem ini juga dilengkapi dengan tampilan secara visual pada monitor menggunakan aplikasi visual basic yang dihubungkan dengan arduino secara serial, sehingga bagi pengguna yang menempati tempat parkir dapat mengetahui tempat parkir yang harus dituju. Tampilan pada monitor menyesuaikan dengan sensor fotodiode yang dipasang pada setiap tempat parkir, Selain itu sistem ini juga akan dirancang agar waktu pencarian lahan parkir oleh pengguna parkir tidak membutuhkan waktu lama. sehingga didapatkan sistem parkir yang aman dan mudah di operasikan.
\end{abstract}

Kata Kunci- Parkir, Mikrokontroler, Database, Image Processing.

\section{Abstract}

Parking management system at this time is still not maximal in the utilization of parking lot, security and time efficiency. in this research, parking system with image processing will be designed, And use two parameters input, using camera to detect the vehicle number plate and modified to text and password (encryption in barcode) obtained randomly. Two parameters are input into database mysql by the system at the entrance, it's the number plate and password, this input is used for vehicles to be out, The system matches between the vehicle number plate and the password, if the license plate and password match with database then satisfy the condition and the doorstop (Motor Servo) is open. This system is also equipped with a visual display on the monitor using visual basic applications associated with serial arduino, so for users who occupy the parking lot can know where to parking place. The display on the monitor adjusts to the photodiode sensor mounted on each parking lot. The parking system that has been made is expected to provide security and comfort facilities so as to facilitate parking access.

\section{PENDAHULUAN}

Jumlah kendaraan di Indonesia mengalami peningkatan yang cukup pesat setiap tahunnya [1]. Seiring dengan peningkatan jumlah kendaraan berdampak juga pada kebutuhan parkir.

Parkir adalah tempat pemberhentian kendaraan dalam jangka waktu pendek atau lama, sesuai dengan kebutuhan pengendara [2]. Parkir merupakan salah satu unsur prasarana transportasi yang tidak terpisahkan dari sistem jaringan transportasi, sehingga sistem pengaturan dan keamanan parkir akan mempengaruhi kinerja jaringan transportasi [2]. Jumlah kendaraan yang berlebih membutuhkan sistem pengelolaan tempat parkir yang tepat, sehingga dapat mengoptimalkan pengelolaan tempat parkir.

Pengelolaan tempat parkir yang dapat dilakukan salah satu contohnya adalah memberikan informasi jumlah kendaraan yang berada di tempat parkir serta status area kepada pengguna parkir. Memberikan informasi tempat kosong dapat memudahkan pengguna parkir dalam mencari tempat parkir, sehingga dalam 
proses pencarian dapat dilakukan secara efektif dan efisien. Meningkatnya jumlah kendaraan serta pengelolaan tempat parkir yang tepat akan meminimalisir pengeluaran biaya yang berlebih karena dilakukan secara cepat.

Dengan adanya pengelolaan sistem yang baik, hal lain yang perlu diperhatikan adalah keamanan dan kenyamanan bagi pengguna parkir. Oleh karena itu, keamanan dan kenyaman yang digunakan dalam pengelolaan parkir ini adalah keamanan menggunakan nomor plat kendaraan dan password, dan memberikan informasi status area kepada pengguna parkir dalam bentuk antarmuka.

Berdasarkan hal tersebut, dibuat skripsi yang berjudul "Rancang Bangun Sistem Keamanan Parkir Berbasis Random Password dan Image Processing Menggunakan Optical Character Recognition (OCR)". Dengan adanya prototipe ini diharapkan dapat membantu menyelesaikan masalah parkir secara efisien. Prototipe dirancang untuk pengelolaan tempat parkir yang otomatis dapat mengoptimalkan penggunaan lahan parkir. Selain itu, dengan adanya pengelolaan parkir maka dapat meningkatkan sistem keamanan parkir. Hal ini dapat memberikan manfaat bagi pengguna parkir serta pengelola parkir, sehingga pengguna parkir dapat merasa aman dan nyaman pada saat parkir. Selain itu pengelola parkir dapat memberikan informasi apabila tempat parkir kosong atau penuh kepada pengguna parkir melalui tampilan antarmuka.

\section{BAHASA DAN METODE}

Metode penelitian yang digunakan pada penelitian ini melalui beberapa tahapan penelitian dan mencari informasi tentang data yang dibutuhkan dalam penelitian. Penelitian pertama adalah pengembangan konsep penelitian berdasarkan daftar pustaka. Selanjutnya perencanaan penelitian meliputi perancangan sistem perangkat keras dan perangkat lunak.

a. Deskripsi Sistem

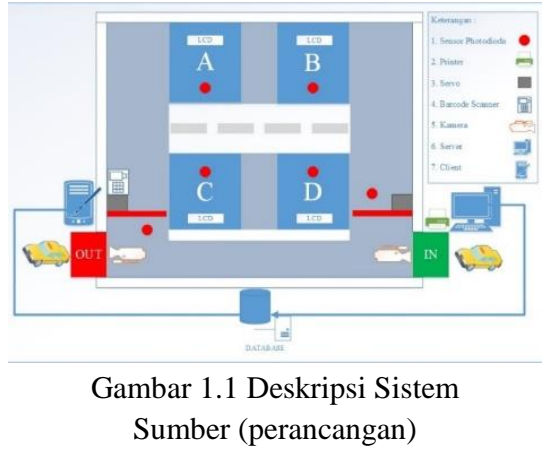

Kendaraan yang masuk berada tepat di depan kamera, kemudian pengguna memilih tempat parkir yang kosong, dan otomatis kamera akan mengambil gambar plat nomor kendaraan, gambar plat tersebut akan diproses oleh sistem menjadi bentuk tulisan (teks) dan disimpan ke dalam basis data bersama dengan kata sandi yang di dapat secara acak. Selain masuk ke basis data, plat dan informasi lain dicetak dalam bentuk karcis melalui sprinter, namun kata sandi yang dicetak sudah di kodekan dalam bentuk barcode.

Setelah itu servo akan menggerakkan pintu untuk membuka, setelah mobil masuk dan melewati sensor fotodiode maka otomatis servo akan menutup.

Ketika berada di dalam mobil diparkir sesuai tempat yang sudah di pesan di awal masuk, mobil yang menutup sensor, maka indikator pada monitor akan menjadi warna merah.

Setelah mobil meninggalkan tempat parkir, indikator pada monitor berubah menjadi hijau, pada tempat keluar pengguna hanya menaruh karcis yang berisikan barcode (sandi) dan menempatkan pada posisi kamera, maka otomatis barcode memindai sandi, ketika sukses kamera otomatis akan mengambil gambar plat kendaraan, kemudian sistem memproses dan menyamakan dengan data yang sudah ada di basis data, jika sandi dan plat nomor sesuai servo akan membuka, dan setelah kendaraan melewati sensor fotodiode, pintu keluar akan menutup.

b. Blok Diagram Sistem

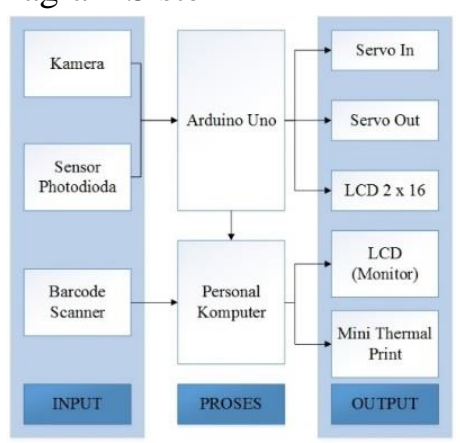

Gambar 1.2 Blok Diagram Sistem Sumber (perancangan) 
Gambar 1.2 merupakan blok diagram sistem parkir, penjelasan blok diagram adalah sebagai berikut :

1. Unit input merupakan unit masukan yang berupa kamera yang berfungsi untuk mengambil gambar plat nomor kendaraan, dan diproses oleh sistem menjadi bentuk teks, sensor fotodiode yang berfungsi untuk mendeteksi apakah ada kendaraan yang berada di tempat atau tidak, kemudian unit input berupa Barcode Scanner, berfungsi untuk scan password yang didapatkan ketika awal masuk.

2. Unit proses terdiri dari personal komputer dan arduino sebagai kontrol, arduino dan komputer sebagai kontrol yang menghubungkan unit input dan unit output, yang saling terintegrasi.

3. Unit output merupakan unit keluaran yang berupa motor servo, berfungsi untuk menggerakkan palang pintu. Kemudian LCD (Monitor Personal Computer) berfungsi untuk menampilkan keadaan tempat parkir apakah sudah terisi atau belum, LCD 2x16 yang berfungsi untuk menampilkan plat nomor kendaraan bahwa tempat sudah dipesan oleh pelanggan, Serta mini thermal print berfungsi untuk mencetak karcis yang berisi sandi.

\section{c. Basis Data $M y S Q L$}

Penggunaan basis data MySql ini digunakan untuk penyimpanan data (nomor plat, sandi, jam dan tanggal) secara online (local network), yang nantinya dapat di akses kembali melalui komputer lain (client).

MySql merupakan perangkat lunak yang portabel, karena bisa dijalankan untuk mengolah basis data Multi platform, selain itu MySql juga dapat diintegrasikan dengan berbagai bahasa pemrograman, seperti yang penulis gunakan, MySql dengan Visual Basic.

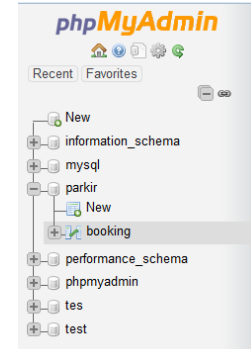

Gambar 1.3 Nama Basis Data Sumber (Screenshot)

\section{d. Perancangan Prototipe}

Rancang bangun tempat parkir berbentuk sangat sederhana namun sudah memenuhi berbagai kondisi sesuai tempat parkir sesungguhnya. Prototipe dibuat menggunakan akrilik dengan tebal $5 \mathrm{~mm}$ untuk dasar, dan $3 \mathrm{~mm}$ untuk bagian lain. Dalam prototipe terdapat empat ruang parkir, satu pintu masuk, dan satu pintu keluar.

Prototipe tersebut berisi kamera pada setiap pintu masuk dan pintu keluar, motor servo pada setiap palang pintu, LCD dan sensor fotodiode pada setiap ruang parkir.

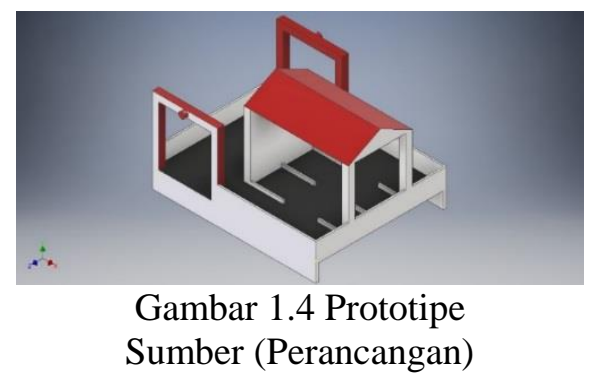

\section{HASIL DAN PEMBAHASAN}

Dalam tahapan pengujian sistem terbagi menjadi beberapa bagian percobaan, di antaranya adalah pengujian $O C R$ dalam menerjemahkan gambar plat nomor, pengujian password barcode apakah ada duplikasi data atau tidak, pengujian sensor fotodiode terhadap tampilan pada GUI Dekstop, pengujian split data LCD 16x2 melalui serial data arduino dan melalui textbox pada GUI Dekstop, pengujian koneksi client server basis data $M y S Q L$, pengujian barcode scanner terhadap barcode pada karcis, dan pengujian total sistem.

\section{Pengujian OCR}

Tingkat akurasi penerjemahan dihitung menggunakan rumus sebagai berikut : 
a. Perhitungan akurasi pendeteksian karakter pada setiap plat nomor kendaraan $\|$ Jumlah karakter benar $\| x \quad 100 \%[8]$

b. Perhitungan akurasi dari total pengujian plat nomor kendaraan

$\left\|\frac{\text { Jumlah data plat nomor berhasil }}{\text { Jumlah sampel citra }}\right\| x$ 100\% $\|$ [9]

Tabel 1 Pengujian Keakuratan OCR Dalam Menerjemahkan Plat Nomor Kendaraan

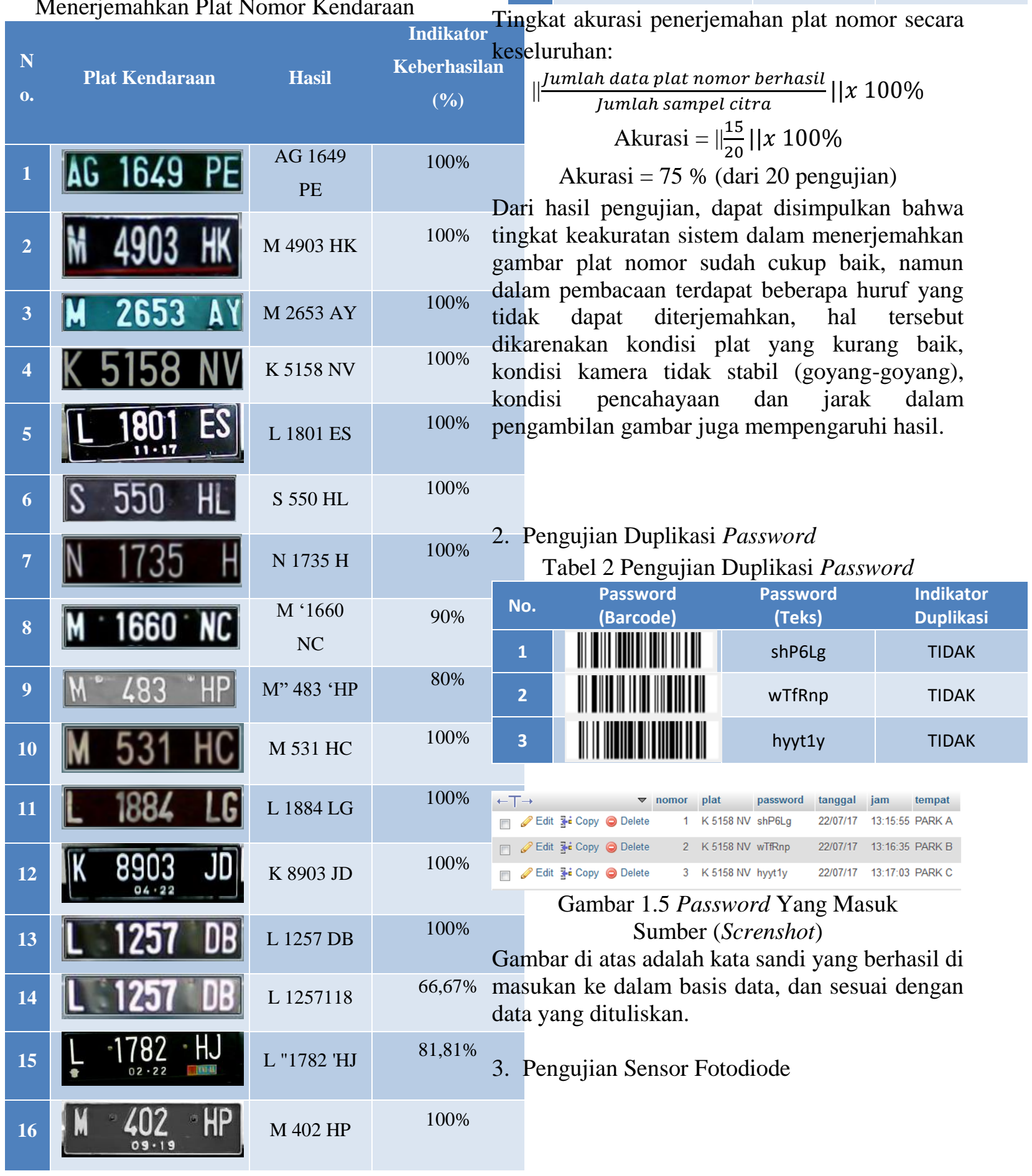


Tabel 3 Pengujian Sensor Fotodiode

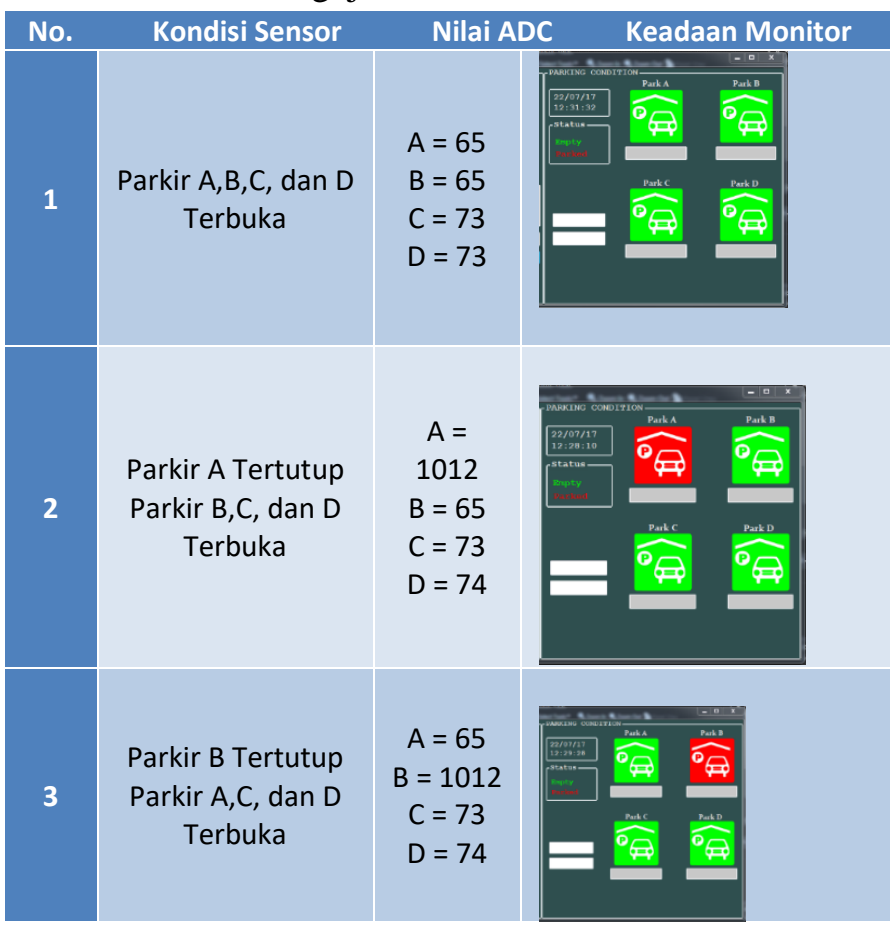

Dari hasil pengujian yang dilakukan, didapatkan hasil seperti uji coba di atas, nilai ADC jika lebih dari batas atau parameter yang telah ditentukan maka warna indikator parkir pada GUI adalah merah, dan jika nilai ADC kurang dari parameter maka indikator warna pada GUI adalah hijau. Penulis menggunakan batas atau parameter nilai ADC 950.

Contoh data pada tabel uji coba 9, nilai ADC Parkir A dan B adalah 65 sedangkan $C$ dan D adalah 1012, maka jika nilai uji coba < nilai batas $=$ hijau dan jika nilai uji coba $>$ nilai batas $=$ merah.

\section{Pengujian Split Data LCD 16x2}

Pengujian split data LCD dilakukan dengan dua cara, yang pertama dengan mengetikkan perintah melalui serial COM dengan format (*isiA,isiB,isiC,isiD,isiSensor,@). Dan yang kedua dengan mengetikkan langsung ke dalam textbox pada GUI.

Pengujian dilakukan dengan tujuan untuk mengetahui pembagian pengiriman data dari serial COM dapat terbagi pada masing-masing LCD atau tidak. Split data dilakukan karena 4 LCD yang digunakan hanya diatur dengan satu microcontroller.

a. Pengujian Melalui Serial COM Arduino

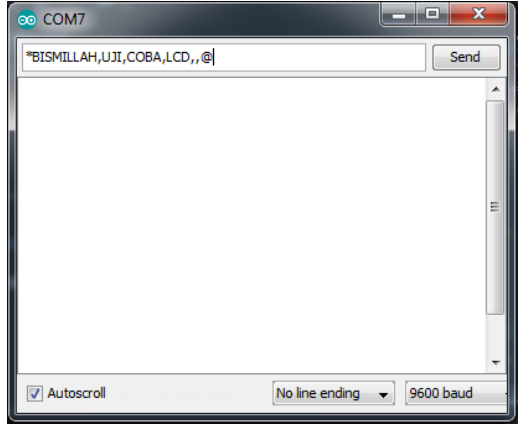

Gambar 1.6 Serial COM Arduino Sumber (Screenshot)

Hasil pada LCD 16x2

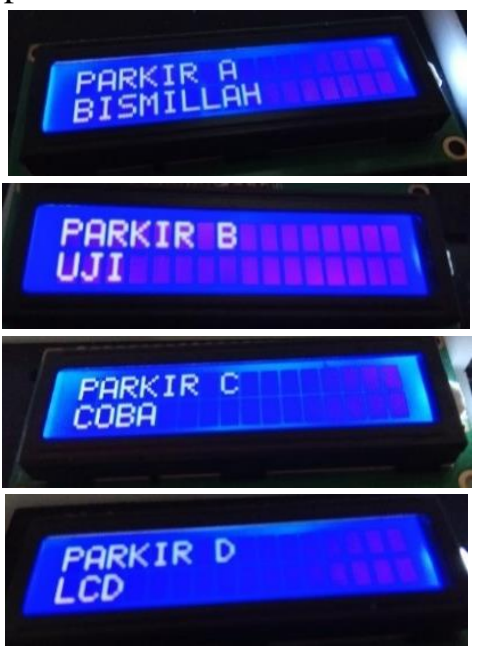

Gambar 1.7 Tampilan LCD 16x2 Sumber (Foto)

b. Pengujian Melalui GUI

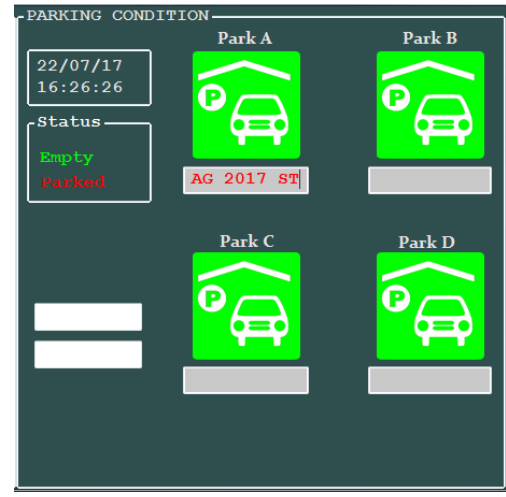

Gambar 1.8 GUI

Sumber (Screenshot)

Hasil Pada LCD 16x2

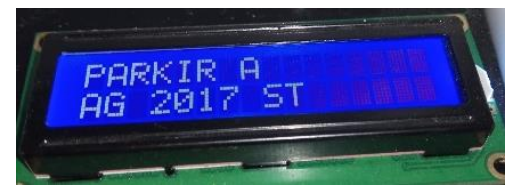

Gambar 1.9 Tampilan LCD 16x2

Sumber (Foto)

Berdasarkan hasil pengujian yang dilakukan, sistem mampu mengirim empat data melalui satu 
serial COM arduino, baik melalui Arduino IDE maupun melalui software visual basic, namun ada tunda (delay) kurang lebih satu detik.

5. Pengujian Barcode Scanner Terhadap Barcode Dalam Karcis

Pengujian barcode scanner dilakukan untuk mengetahui tingkat keakuratan barcode sacanner terhadap karcis yang telah di cetak, karcis untuk pengujian di cetak sebanyak 10 karcis.

Berikut adalah hasil pengujian barcode scanner terhadap barcode.

Tabel 4 Pengujian Barcode Scanner dengan baik baik dari rangkaian elektronika, basis data, dan aplikasi GUI.

b. Pengacakan kata sandi dalam sistem dapat berjalan $100 \%$ tanpa duplikasi atau pengulangan dalam beberapa pengujian, tingkat keandalan image processing dan $O C R$ dalam menerjemahkan gambar plat nomor kendaraan sudah mencapai $75 \%$.

c. Sensor fotodiode cukup baik dalam penggunaan sebagai indikator kondisi tempat parkir kendaraan, tingkat akurasi sensor yang terhubung dengan GUI mencapai $100 \%$ dalam pengujian pada ruangan dengan cukup cahaya.

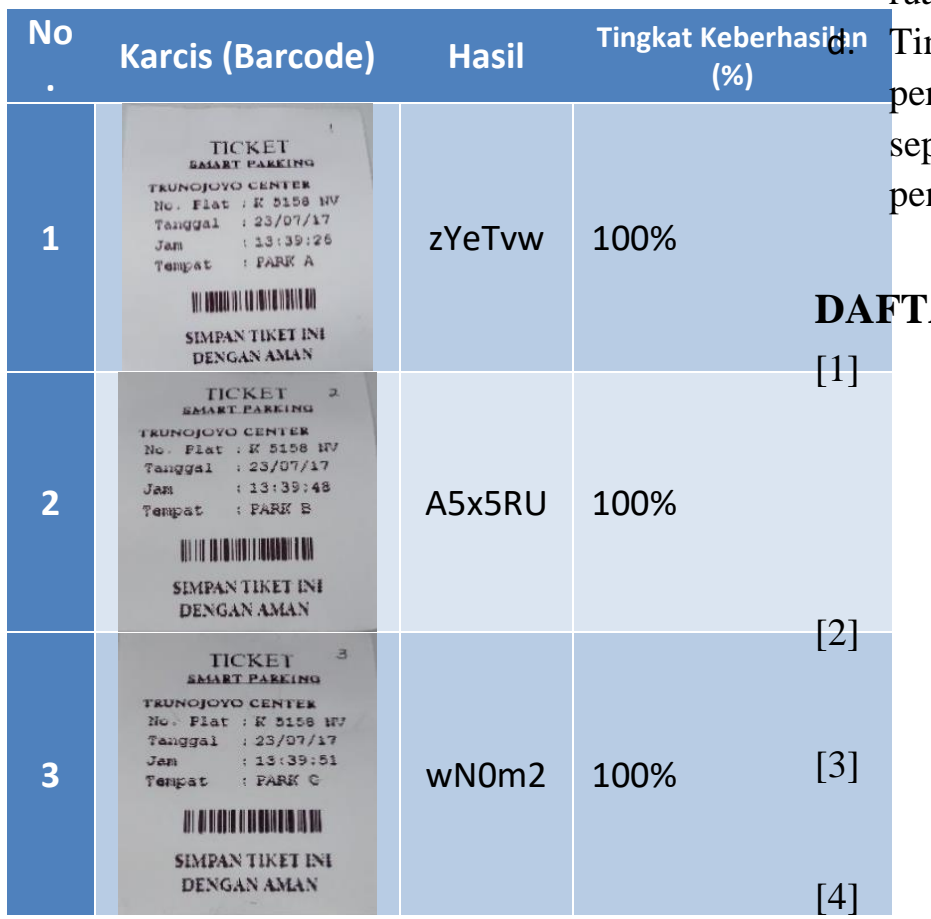

Berdasarkan pengujian yang di lakukan, barcode scanner dapat memindai barcode yang ada pada karcis dengan baik, namun ada beberapa pengujian yang diulang dua hingga tiga kali agar barcode scanner dapat memindai barcode tersebut.

\section{KESIMPULAN}

Berdasarkan hasil perancangan, implementasi dan pengujian hasil dari prototipe dan sistem yang telah dibuat dapat ditarik kesimpulan sebagai berikut :

a. Prototipe atau sistem parkir berbasis random password dan image processing yang telah dibuat dapat bekerja dengan yang diharapkan, sistem sudah terintegrasi
Tingkat efisiensi sistem yang meliputi perangkat lunak dan perangkat keras sudah seperti yang diharapkan, dan tingkat akurasi penerjemahan plat sudah baik.

\section{DAFTAR PUSTAKA}

"Badan Pusat Statistik," Perkembangan Jumlah Kendaraan Bermotor Menurut Jenis tahun 1987-2013, 5 Desember 2014. [Online]. Available: http://www.bps.go.id/linkTabelStatis/vie w/id/1413. [Diakses 21 Desember 2016]. "Catatan Kuliah Rekayasa Lalu Lintas," Universitas Sebelas Maret, Surakarta, 2006.

J. Phil, Visual Basic: A Complete Course Letts Higher Education List Series, Cengage Learning EMEA, 2001.

D. C. Malmoe, Arduino, Sweden, 2011. M. K. Soraya, Z. Raamar, G. M dan Giaglis, "Advances in Ubiquitous Computing: Future Paradigms and Directions," IGI Publishing, 2008.

D. Sawicz, "Hobby Servo Fundamentals".

F. G. Jacek, Permanent Magnet Motor Technology: Design and Applications, Third Edition, CRC Press, 2011.

[8] A. Solichin and Z. Rahman, "Identifikasi

Plat Nomor Kendaraan Berbasis

Mobile," TICOM, vol. 3, p. 3, 2015

[9] R. P. Wicaksana, "Pengenalan Plat Nomor Kendaraan Secara Otomatis," ITS, Surabaya, 2013. 